electrode potentials are almost identical : $0.799 \mathrm{v}$. for $\mathrm{Hg}: \mathrm{Hg}_{2} \cdot$ and $0.798 \mathrm{v}$. for $\mathrm{Ag}: \mathrm{Ag} \cdot$ at $25^{\circ} \mathrm{C}$. In the hardening of plastic dental amalgams, $\mathrm{Ag}_{3} \mathrm{Hg}_{4}$ is formed by the reaction

$$
\underset{\text { flings }}{\mathrm{Ag}_{3} \mathrm{Sn}}+\underset{\text { liquid }}{\mathrm{Hg}} \rightleftarrows \underset{\text { dendrites }}{\mathrm{Ag}_{3} \mathrm{Hg}_{4}}+\underset{\begin{array}{c}
\text { solid solution } \\
\text { (Black, Troiano) }
\end{array}}{\mathrm{Sn}(\mathrm{Hg})}
$$

Densities of heterogeneous silver amalgams. The variation of density with composition has been deter. mined for the heterogeneous range. Although the solubility of silver in mercury is small--only about 0.03 per cent at room temperature-they are quite fluid up to about 8 per cent. Between about 8 per cent and about 20 per cent silver, they are plastic on formation but 'set' on standing overnight; above 20 per cent they resemble hard 'Plasticine' rather than a heterogeneous mass, becoming gradually harder as the composition of the solid amalgam is approached. This was found to be 27.43 and 27.72 per cent in two separate experiments, by expulsion of the liquid phase (argentiferous mercury) under severe compression. By very careful handling of the set amalgams, it was found possible to use Archimedes' method down to about $13 \frac{1}{2}$ per cent silver; below this a special midget ( $2 \frac{1}{2} \mathrm{ml}$.) specific gravity bottle was used with success. The results are in fair agreement with the older determinations of Mrey (1905), but are more consistent among themselves and probably rather more accurate than these; the very erratic values reported by Joule (1863) and Duczko (1935) were not confirmed. The density/composition curve shows small but distinct peaks at about 15 and 28 per cent, about $13 \cdot 61$ and $13 \cdot 60$ respectively, with minima at about 13 and 25 per cent, that is, $13 \cdot 47$ and $13 \cdot 37$. Between these points the curve is made up of straight lines and the density is invariably above that calculated for a conglomerate by summation of volumes. The silver content (at the mercury boundary) lies about midway between $\left(\mathrm{Ag}_{3} \mathrm{Hg}_{4}\right)_{4}$ proposed by Weryha (28.74 per cent), and $\left(\mathrm{Ag}_{2} \mathrm{Hg}_{3}\right)_{10}$ proposed by Berman and Harcourt (26.4 per cent), but a Hume-Rothery constitution $\left(\mathrm{Ag}_{5} \mathrm{Hg}_{8}\right)_{4}$ is definitely excluded by present results as well as by $X$-radiological and metallographic data.

Setting and Thixotropy. The amalgams set like plaster of Paris when they contain more than 8 per cent silver, but the process is very different, being completely and repeatedly reversible by pressure alone. During setting, the hardness increases ; above 20 per cent one can obtain a robust mass which becomes quite plastic on kneading. This process is thixotropic, being due to the formation of a welldefined reseau of acicular crystals, which is quickly degraded under local pressure. Surplus mercury is held in this spongy structure as a result of its high surface tension, and in the mercury-rich amalgams may be seen to liquate out, leaving the dry réseau intact. It is rare to find thixotropy displayed so perfectly as in these amalgams.

Effect of setting on density. With the incidence of setting there is also a fall in density of $1-1 \frac{1}{2}$ per cent in a few days. In an extreme case, a 15 per cent alloy, which had stood undisturbed for more than two years, segregated into hard discrete equi-axed lumps and argentiferous mercury. Hard grinding was required to restore this to the plastic state, when its density was found to be normal and as much as 4 per cent greater. This ('pea' plus liquid) state is regarded as the ultimate limit of thixotropic setting, equivalent to complete spheroidization of cementite in steel. Two explanations are suggested.
(1) That pressure causes Murphy's peritectic reaction at $127^{\circ} \mathrm{C}$. to go leftward at room temperature. $\beta+\mathrm{Hg} \rightleftarrows \gamma$, or very nearly $3 \mathrm{AgHg}+\mathrm{Hg} \rightleftarrows \mathrm{Ag}_{3} \mathrm{Hg}_{4}$.

(2) That the reseau consists of another intermetallic species, formed on standing and restored on kneading to the $\mathrm{Ag}_{3} \mathrm{Hg}_{4}$ originally present. This species might be either the same phase $(27 \cdot 7$ per cent silver) in another space lattice with different physical properties, or a new intermetallic compound, possibly of different composition. Unfortunately, the relative proportion of jagged crystals and argentiferous mercury in the 15 per cent amalgam was not deter. mined accurately. It may be estimated to be about $1: 2$, which would give an approximate silver content of about 45 per cent, the solubility of silver in liquid mercury being very small at room temperature. One may recall Murphy's $\beta$-constituent containing about 40 per cent mercury, which we have denoted $\mathrm{AgHg}$.

Dental amalgams. The unexpectedly low density of the set structure (spongy réseau plus argentiferous mercury) accounts very happily for the paradoxical expansion of tooth stoppings too rich in silver-a sharp change in setting characteristics takes place at 25 5-26 per cent. This bugbear led to the postulation of void formation by Gray, which faute de mieux has been accepted by Troiano and Gayler. However, in the specimen mentioned, in which the thixotropy had proceeded to the extreme limit, the measured difference of 4 per cent in density would require a void volume of as much as one eighth in the 'peas'. In view of their hardness and jagged nature, this is very difficult to accept. Moreover, it is somehow repugnant to scientific intuition to believe that voids can be formed on dendritic erystallization within a mother liquor with surface energy as high as mercury. Sullivan's amalgam of precipitated copper and mercury, now discarded in dentistry, is plastic but sets hard in a few hours, and can then be rolled or hammered. On kneading or heating, the mass recovers its plasticity.

Application to other physical properties. It is formally suggested that other anomalies in the physical properties of amalgams of alkalis and other metals, for example, viscosity, surface tension, electrical conductance, may also be due to thixotropy rather than to colloid formation.

\section{A SIMPLE TECHNIQUE FOR PHOTOMICROGRAPHY}

\section{By DR. W. N. LEAK}

$T^{O}$ record of a microscopical preparation can com1 pare in value with a photograph, yet photomicrographs are often not taken so frequently as workers might wish because of the difficulty of doing the work personally or the interruption caused by sending it to a special photomicrographical department. There is, however, a simple method of obtaining excellent photomicrographs. The method depends on the fact that a camera will photograph a virtual image as easily as it will a real object. The image in a microscope is a virtual one, and if this is focused, as it normally is, at infinity, and a camera, also focused at infinity, is placed as near as possible to the ocular, so that all the light coming through the ocular enters the camera lens, a good photograph will result if the exposure is correct and the camera truly in line with the microscope tube. In actual practice this can be judged sufficiently well by eye, 


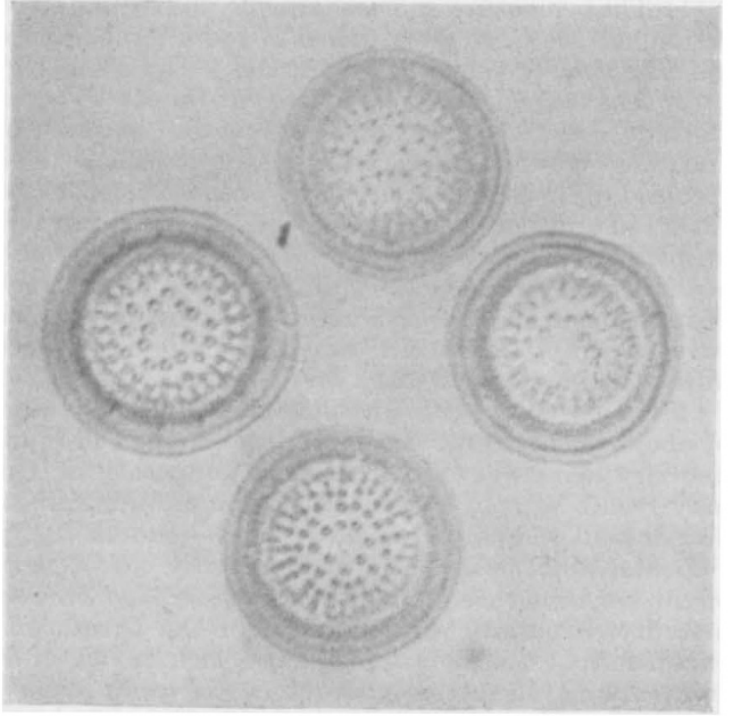

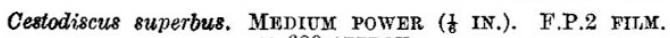
$\times 600$ APPROX.

and the actual taking of a photomicrograph by this method presents no real difficulty whatever. We can ensure that the microscope image is focused at infinity either by using a focusing screen or a reflex camera, but much more simply by viewing part of the image through a small telescope (a 4-in. lens with a spare eyepiece in a cardboard tube makes quite a satisfactory one) focused for infinity and altering the fine adjustment until the image is sharp. Even this simple procedure is not necessary if the observer's eye is quite normal.

The excellence of the results obtained by this method seems to be due to two factors. First, practically all microscopes are constructed to give their finest results when used visually with an eyepiece, ete., and these conditions do not obtain in the ordinary methods of photomicrography. In the present method, however, we make the microscope give the finest visual image of which it and we are capable, and then photograph this image with the best photographic equipment at hand. The second reason is that in the ordinary way there is a considerable distance between ocular and plate, and this is liable to give rise to serious diffraction phenomena.

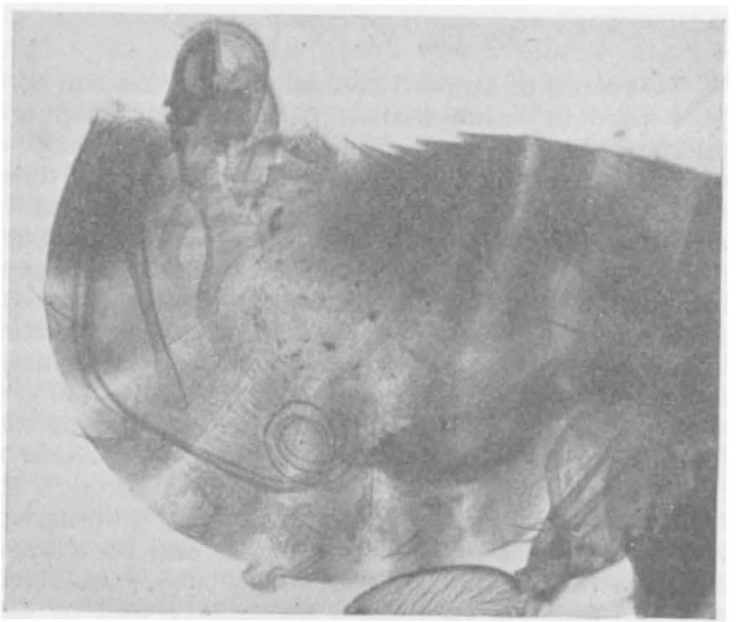

TAIL OF MALE FLea. LOW POWER (1 IN.). H.P.2 FILM.
In this method, however, the length of these narrow pencils of light is scarcely greater than the focal length of the camera lens, so that diffraction troubles almost cease to exist.

With a 10-in. camera lens, the image on the film will be the same size as that seen by the eye, and such a film should stand considerable enlargement; though actually I find that my Leica with a 2 -in. Elmar lens will reproduce practically everything I can see if fine grain film is used and enlarged about eight times. To illustrate this the photograph of Cestodiscus superbus was deliberately taken at the lowest visual magnification to show the marginal striations comfortably and the film enlarged eight times. A 4-in. or 5-in. lens might be better for general use, though longer exposures would be required. Kodachrome or Agfacolor film have even finer resolution than fine-grain film. With this method there is nothing to prevent the use of high-power eyepieces, for the close eyepoint and the shadows on the retina of blood vessels and opacities, etc., which make them objectionable for visual use do not affect the camera lens. I do not imply that this will give resolution beyond the resolving power of the objective, but it may well show details on the enlarged print which many eyes would fail to see visually.

I hope this brief description of some of the practical and theoretical points involved will make the method better known, for it has great possibilities in industrial and academic research, as well as in teaching. The method can naturally also be used for obtaining a photograph through any other instrument which uses an eyepiece, such as telescope, spectroscope, etc. A fuller description of the method appeared in the British Medical Journal of December 18,1943, p. 787 .

\section{SOME SOUTH AMERICAN TIMBERS}

TWO Leaflets, Nos. 31 and 32 (September 1943), I have been issued under the auspices of the Department of Scientific and Industrial Research by the Forest Products Research Laboratory on "Some Foreign Timbers (South America), 3 and 4" respectively. The leaflets deal with the tree, timber, seasoning and mechanical properties, natural durability, insect attack, preservative treatment, working qualities, uses, and supplies available.

In Leaflet No. 31 two trees, the parana pine, Araucaria brasiliana and louro vermelho, probably Ocotea rubra, are discussed. The parana pine is a sub-tropical conifer attaining a height of $110-130 \mathrm{ft}$. with an average diameter of $2 \mathrm{ft}$. and clear bole of 60-70 ft. It occurs in the Andean region of South America at varying altitudes above 1,600 ft. and preferably on sandy soils. The timber is not resistant to decay, and sapwood very liable to develop a blue stain ; it is easily worked by hand and machine tools.

Louro vermelho attains a height of more than $100 \mathrm{ft}$. and a maximum diameter of $3 \mathrm{ft}$. in some parts of its range, which probably includes Brazil and British Guiana and may extend further. The timber is said to be resistant to decay, probably more resistant than the heartwood of English oak; a character which, should it be confirmed, is high praise indeed. It is said to be easily workable with hand and machine tools.

Leaflet No. 32 gives notes on peroba rosa, Aspidosperma polyneuron (syn. A. peroba); and mandio. 